Tropical Journal of Pharmaceutical Research October 2011; 10 (5): 663-669

(C) Pharmacotherapy Group,

Faculty of Pharmacy, University of Benin

Benin City, 300001 Nigeria.

All rights reserved.

Available online at http://www.tjpr.org

Research Article

http://dx.doi.org/10.4314/tjpr.v10i5.16

\title{
Development and Validation of a Bioanalytical Method for Direct Extraction of Diclofenac Potassium from Spiked Plasma
}

\author{
Attia Sarfraz ${ }^{1,2^{\star}}$, Muhammad Sarfraz $^{1,2}$ and Mahmood Ahmad ${ }^{1}$ \\ ${ }^{1}$ Faculty of Pharmacy and Alternative Medicines, The Islamia University of Bahawalpur, ${ }^{2}$ Department of Pharmacy, \\ The University of Lahore, Pakistan.
}

\begin{abstract}
Purpose: To develop and validate a user-friendly spiked plasma method for the extraction of diclofenac potassium that reduces the number of treatments with plasma sample, in order to minimize human error. Method: Instead of solvent evaporation technique, the spiked plasma sample was modified with $\mathrm{H}_{2} \mathrm{SO}_{4}$ and $\mathrm{NaCl}$, respectively, and then the drug was extracted after vortexing the sample with acetonitrile as precipitating agent. The separation of diclofenac potassium and internal standard (ketoprofen) was achieved at preset conditions: $5 \mu \mathrm{m}$ ODS Hypersil C-18 $(4.0 \mathrm{~mm} \times 250 \mathrm{~mm})$ column, eluted with $50 \%$ acetonitrile in water $(\mathrm{V} / \mathrm{V})$ as mobile phase containing ammonium acetate and triethylamine (TEA), at a

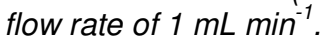

Results: The peaks of the drug and internal standard (I.S.) were resolved at $14 \pm 1$ min and $7 \pm 1$ min, respectively. The calibration curve and linearity were determined over the concentration range of 0.25 to $40 \mu \mathrm{g} \mathrm{mL}$ and they were linear $\left(r^{2}=0.9991\right.$ and 0.9982 , respectively $)$. The accuracy was $>81.32 \%$. Limit of detection and limit of quantification were 0.05 and $0.25 \mu \mathrm{g} \mathrm{mL}^{-1}$, respectively, while the recovery range for diclofenac potassium and ketoprofen was more than 79 and $85 \%$, respectively. The absolute average difference of 0.18 between the observed concentrations for intra- and inter-day studies indicated that the sample was stable for over one month.

Conclusion: The proposed method may be applied to routine bioanalysis, particularly for NSAIDs, due to its high sensitivity, specificity, repeatability, reproducibility, robustness and ruggedness.
\end{abstract}

Keywords: Bioanalytical method, Diclofenac potassium, RP-HPLC method, NSAIDs, Plasma 


\section{INTRODUCTION}

Diclofenac potassium is a faintly yellowish white to light beige, virtually odorless, slightly hygroscopic crystalline powder. It is freely soluble in methanol, soluble in ethanol and water, and practically insoluble in chloroform and in dilute acid. The n-octanol/water partition coefficient is 13.4 at $\mathrm{pH} 7.4$ and 1545 at $\mathrm{pH}$ 5.2. It has a single dissociation constant (pKa) of $4.0 \pm 0.2$ at $25^{\circ} \mathrm{C}$ in water [1]. Diclofenac potassium (Diclo-K) is a substituted phenyl-acetic acid derivative and widely used in the management of many inflammatory conditions [2-3]. It also has analgesic and antipyretic actions. In spite of its pharmacological importance, relatively few studies are known to explain analytical quantification of diclofenac potassium in human plasma.

HPLC is a powerful tool for analyzing small analytes such as drugs in biological samples. However, analysis of analytes present in matrices such as plasma requires welldesigned sample preparation procedures such as protein precipitation, centrifugation, extraction and filtration that can introduce experimental errors and ultimately reduce precision and accuracy of measurement [34]. An attractive approach would be to reduce the number of treatments in sample preparation procedure in order to minimize human and non-human errors. Reverse phase high performance liquid chromatography (RP-HPLC), a bonded phase chromatographic technique, uses water as a base solvent. Separation based on solvent strength and selectivity also may be affected by column temperature and $\mathrm{pH}$. In general, the more polar component (diclofenac potassium) elutes faster than the less polar one [4]. In the $\mathrm{pH}$ range 2 - 8, RPHPLC resolves polar components efficiently [5].

The aim of this work was to develop a simple, accurate, reproducible and sensitive method for the determination of diclofenac potassium in human plasma using rapid, convenient and simple liquid-liquid extraction and reverse phase HPLC method based on UV-visible detection [6].

\section{EXPERIMENTAL}

\section{Materials}

All the reagents used were of analytical grade. Diclofenac potassium was donated by PDH Pharmaceuticals Pvt Ltd, Lahore, ketoprofen by Sanofi Aventis Limited Karachi, Pakistan. Acetonitrile, methanol, ammonium acetate, triethylamine (TEA), sodium chloride, sulphuric acid and ortho-phosphoric acid 85 $\% v / v$ were obtained from Merck, Germany. HPLC grade water was obtained using a water distillation appratus (model, IM-100, Irmeco $\mathrm{GmbH}$, Germany) and filtered, prior to use, through a vaccum filter assembly (Sartorius Goettingen, Germany) containing a cellulose acetate filter of $0.45 \mu \mathrm{m}$ pore size.

\section{Instrumentation}

HPLC (Perkin Elmer, Series 200, USA) with TCNav software, consisted of a binary pump solvent delivery system, an ultraviolet-visible (UV-Vis) variable wavelength detector, integrator $\mathrm{NCl} 900$ was used. Samples were introduced into a Rheodyne $20 \mu \mathrm{L}$ fixed-loop injector with a $50 \mu \mathrm{L}$ glass syringe. Chromatographic separation was performed on a $5 \mu \mathrm{m}$ particle size, $4.0 \mathrm{~mm}$ x $250 \mathrm{~mm}$ ODS Hypersil C18 stainless steel analytical column (Thermo Electron Corporation, UK). All solvents were degassed with a sonicator (Elma D78224, Germany) and pH were checked with a pH meter (Inolab, Series WTW, Germany) prior to use.

\section{Preparation of mobile phase}

To prepare $1 \mathrm{~L}$ of mobile phase, $500 \mathrm{~mL}$ of HPLC grade water was added to $500 \mathrm{~mL}$ of acetonitrile. Freshly prepared $0.1 \mathrm{M}$ ammonium acetate $(2 \mathrm{~mL})$ and $100 \mu \mathrm{L}$ TEA were added, consecutively, to the mixture. This order of mixing was strictly maintained throughout the study. The $\mathrm{pH}$ of the mobile 
phase was adjusted to 3.0 using orthophosphoric acid. The mobile phase was prepared daily and was not recycled during use.

\section{Preparation of stock solution}

Stock solution of diclofenac potassium was freshly prepared in $50 \%(\mathrm{v} / \mathrm{v})$ aqueous acetonitrile to give a final concentration of 1 $\mathrm{mg} \mathrm{mL}^{-1}\left(1000 \mu \mathrm{g} 1000 \mathrm{\mu L}^{-1}\right)$. Working solutions of diclofenac potassium were prepared in $50 \%(\mathrm{v} / \mathrm{v})$ acetonitrile by appropriate dilutions to give appropriate concentrations of $0.05,0.1,0.25,0.5,1.0$, $2.5,5.0,10,20$ and $40 \mu \mathrm{g} \mathrm{mL}$. All the solutions were stored at $-20^{\circ} \mathrm{C}$ and protected from light.

Stock solution of the internal standard (ketoprofen) was prepared with $50 \%(\mathrm{v} / \mathrm{v})$ acetonitrile to give a concentration of $1 \mathrm{mg}$ $\mathrm{mL}^{-1}\left(1000 \mu \mathrm{g} 1000 \mu \mathrm{L}^{-1}\right)$ and then further diluted to $250 \mathrm{\mu g} \mathrm{mL}^{-1}$.

\section{Spiked plasma method}

The modified method $[7,8]$ involved acidifying $500 \mu \mathrm{L}$ of plasma sample, containing $20 \mu \mathrm{L}$ of Diclo-K and $50 \mu \mathrm{L}$ of $250 \mu \mathrm{g} \mathrm{mL} \mathrm{L}^{-1}$ ketoprofen (I.S), with $500 \mu \mathrm{L}$ of $1.74 \mathrm{M}$ sulphuric acid. The plasma sample was modified with $20 \mu \mathrm{L}$ of $3 \mathrm{M} \mathrm{NaCl}$ and vortexed for 1 min $[9,10]$. Acetonitrile $(500 \mu \mathrm{L})$ was added and vortexed for $30 \mathrm{~s}$. The order of mixing was maintained throughout the study. The resultant mixture was centrifuged at $3000 \mathrm{rpm}$ for $10 \mathrm{~min}$. The supernatant was separated in Eppendrof tubes. An aliquot $(20 \mu \mathrm{L})$ of this supernatant was chromatographed.

\section{Preparation of standard curve}

A standard curve was prepared by spiking $500 \mu \mathrm{L}$ plasma samples with $20 \mu \mathrm{L}$ of one of the working solutions prepared above to produce calibration curve points equivalent to $0.05,0.1,0.25,0.5,1.0,2.5,5.0,10,20$ and $40 \mu \mathrm{g} \mathrm{mL}^{-1}$ of diclofenac potassium.
Each suppernatant $(20 \mu \mathrm{L})$ was injected with a $50 \mu \mathrm{L}$ HPLC syringe and absorbance was taken at $276 \mathrm{~nm}$. All the tests were performed in triplicate.

\section{Extraction recovery}

Recovery was determined by comparing the values of the peak area of spiked plasma and its relevant solution using Eq 1.

$\%$ Recovery $=($ Diclo-K ext $/$.S $) /\left(\right.$ Diclo- $K_{\text {non- }}$ ext/I.S) x 100

where Diclo-K ext $/ \mathrm{I} . \mathrm{S}=$ area ratio of extracted diclofenac potassium to ketoprofen, and Diclo- $K_{\text {non-ext }} / \mathrm{I} . S=$ area ratio of solution of diclofenac potassium to ketoprofen

\section{Method validation}

The method was validated in accordance with European Medicines Evaluation Agency (EMEA) guidelines [11] on validation of bioanalytical methods. General tests performed were: recovery, accuracy, precision, reproducibility, linearity, specificity, limit of detection and quantification and ruggedness [12-14].

\section{Specificity (Selectivity)}

To evaluate the specificity of the developed method, placebo and appropriate test sample (spiked plasma) were run in triplicate on HPLC the preset conditions and the results compared, statistically.

\section{Linearity of the calibration line/range}

The calibration plots for the analyte in plasma were prepared by spiking drug-free plasma with standard stock solutions to yield concentrations of $0.25-40.0 \mu \mathrm{g} \mathrm{mL}{ }^{-1}$ for diclofenac potassium. The linearity among nominal concentrations and observed peak area ratio was calculated by least squares method using regression line. 


\section{Accuracy and bias}

Accuracy and bias were determined for the developed method by performing measurements in consecutive and nonconsecutive sequences. For single analyte detection, the linearity was determined within the range of $50-150 \%$ or $60-140 \%$ or 80 $-120 \%$ of the target concentration. Accuracy was calculated as in Eq 2.

Accuracy $(\%)=\left(C_{\text {Obs. Mean }} / C_{\text {Nom }}\right) \times 100$

Experimental errors in the test were determined using the values of standard deviation (SD) and standard error mean (SEM) while the accuracy of the results in consecutive and non-consecutive fashion was defined by values of the $95 \%$ confidence of interval $(95 \% \mathrm{Cl})$ at lower $(\mathrm{L})$ and upper limits (U).

\section{Precision}

It was desirable to have an injection precision in terms of relative standard deviation (RSD). The precision of the method was defined with the existence of the results in range, i.e., 0 10 [15-18]. The results of the developed method were validated by inter-day precision after one month.

\section{Limits of detection (LOD) and Quantifi- cation (LOQ)}

The LOD for extracted diclofenac potassium from spiked plasma sample was measured at signal to noise $(\mathrm{S} / \mathrm{N})$ ratio of $2: 1$ with precision and accuracy. To determine LOD and LOQ, the plasma samples were chromatographed with descending order of the spiked concentrations of analyte. Based on the relative standard deviation (RSD) obtained, the LOQ was subsequently validated by replicate analysis ( $\geq \square 6)$ of samples prepared around this concentration. The LOD was taken as $0.2 \times$ LOQ [19] and validated by comparing the known low concentrations with blank samples $(n \geq 6)$ [20].

\section{RESULTS}

First, this method was implemented for the extraction of diclofenac potassium. Thereafter, it was applied to extract ketoprofen as well. The peak areas were noted for each concentration under preset conditions shown in Table 1.

Table 1: Optimal chromatographic conditions

\begin{tabular}{ll}
\hline Parameter & Specification \\
\hline Column & $5 \mu \mathrm{m}$ ODS Hypersil C-18 \\
& $(4.0 \mathrm{~mm} \times 250 \mathrm{~mm})$ \\
Guard column & Uniguard TEC \\
Mobile phase & $50 \%$ acetonitrile $(100$ \\
& $\mathrm{mL})+0.1 \mathrm{M}$ ammonium \\
& acetate $(2 \mathrm{~mL})+$ TEA $(10$ \\
& $\mu \mathrm{L})$ \\
Flow rate & $1.0 \mathrm{~mL} \mathrm{~min}{ }^{-1}$ \\
Detection wavelength & $276 \mathrm{~nm}$ \\
Sensitivity & $0.2 \mathrm{AUFS}$ \\
Injection volume & $20 \mu \mathrm{L}$ \\
Retention time of IS & $7 \pm 1 \mathrm{~min}$ \\
Retention Time of & $14 \pm 1 \mathrm{~min}$ \\
drug & \\
Temperature & Ambient \\
\hline
\end{tabular}

The recovery values (mean \pm SEM) of diclofenac potassium and ketoprofen were $98.09 \pm 5.42$ and $104.5 \pm 6.76$, respectively. Bias of the results are shown in Table 2.

Table 2: Recovery data for diclofenac potassium and ketoprofen

\begin{tabular}{|c|c|c|c|c|}
\hline \multirow{2}{*}{$\begin{array}{l}\text { Nominal } \\
\text { conc. } \\
(\mu \mathrm{g} / \mathrm{mL})\end{array}$} & \multirow{2}{*}{$\begin{array}{c}\text { Ketoprofen } \\
\begin{array}{c}\text { Recovery } \\
(\%)\end{array} \\
\end{array}$} & $\begin{array}{l}\text { Diclofenac } \\
\text { potassium }\end{array}$ & \multirow[b]{2}{*}{$\begin{array}{c}\text { Recovery } \\
(\%)\end{array}$} & \multirow[b]{2}{*}{ Bias } \\
\hline & & Bias & & \\
\hline 0.25 & 85.54 & 14.46 & 116.91 & -16.91 \\
\hline 0.50 & 96.10 & 3.90 & 104.06 & -4.06 \\
\hline 1.00 & 126.51 & -26.51 & 79.04 & 20.96 \\
\hline 2.50 & 141.77 & -41.77 & 70.54 & 29.46 \\
\hline 5.00 & 99.54 & 0.46 & 100.46 & -0.46 \\
\hline 10.00 & 94.58 & 5.42 & 105.73 & -5.73 \\
\hline 20.00 & 95.60 & 4.40 & 104.61 & -4.61 \\
\hline 40.00 & 96.77 & 3.23 & 103.34 & -3.34 \\
\hline
\end{tabular}


The selectivity of the developed method was good based on the fact that there was no interfering peak in the chromatograms (not shown) at the retention time of diclofenac potassium. Both drugs (diclofenac potassium and ketoprofen, i.e., IS) were separated sufficiently at $14 \pm 1 \mathrm{~min}$ and $7 \pm 1 \mathrm{~min}$, respectively. The calibration equation $(y=$ $20132 x-1740$, with $R^{2}=0.9991$ ) indicated a high degree of linearity as well as specificity of the method. At lower concentrations of diclofenac potassium, i.e., 0.25 and $0.5 \mu \mathrm{g}$ $\mathrm{mL}^{-1}, \%$ recovery of the sample was in a wider range thus indicating lower accuracy of the results due to sensitivity of the HPLC method at lower concentrations as shown in the Table 3.
It was observed that the accuracy of the results for developed method was better for higher concentrations than for lower concentrations of the drug as shown in Table 3. Precision was considered with intra- and inter-day performance of the developed method, as shown in Tables 4 and 5.

All the results were within the defined range except for the lower concentration, i.e., 0.25 $\mu \mathrm{g} \mathrm{mL}^{-1}$ in intra-day study. Inter-day statistics also showed the stability of the extracted sample at $-20 \stackrel{\circ}{\circ}$. The LOD was $0.05 \mathrm{\mu g} \mathrm{mL}^{-1}$. The quantifiable concentration for diclofenac potassium in biological sample was $0.25 \mu \mathrm{g}$ $\mathrm{mL}^{-1}$ under the stated HPLC conditions.

Table 3: Accuracy and bias data for diclofenac potassium

\begin{tabular}{lllllllll}
\hline $\begin{array}{l}\text { Nominal conc. } \\
\left(\mu \mathrm{g} \mathrm{mL}^{-1}\right)\end{array}$ & $\mathbf{0 . 2 5}$ & $\mathbf{0 . 5 0}$ & $\mathbf{1 . 0 0}$ & $\mathbf{2 . 5 0}$ & $\mathbf{5 . 0 0}$ & $\mathbf{1 0 . 0 0}$ & $\mathbf{2 0 . 0 0}$ & $\mathbf{4 0 . 0 0}$ \\
\hline $\begin{array}{l}\text { Mean observed conc. } \\
\left(\mu \mathrm{g} \mathrm{mL}^{-1}\right)\end{array}$ & 0.43 & 0.67 & 0.93 & 2.03 & 4.60 & 10.37 & 20.00 & 39.90 \\
SD & 0.12 & 0.15 & 0.15 & 0.21 & 0.20 & 0.21 & 0.00 & 0.17 \\
SEM & 0.07 & 0.09 & 0.09 & 0.12 & 0.12 & 0.12 & 0.00 & 0.10 \\
$95 \% \mathrm{Cl}(\mathrm{L})$ & 0.15 & 0.29 & 0.55 & 1.52 & 4.10 & 9.85 & 20.00 & 39.47 \\
$95 \% \mathrm{Cl}(\mathrm{U})$ & 0.72 & 1.05 & 1.31 & 2.55 & 5.10 & 10.88 & 20.00 & 40.33 \\
Bias & 0.18 & 0.17 & -0.07 & -0.47 & -0.40 & 0.37 & 0.00 & -0.10 \\
Accuracy (\%) & 173.32 & 133.34 & 93.33 & 81.32 & 92.00 & 103.70 & 100.00 & 99.75 \\
\hline
\end{tabular}

Table 4: Intra-day statistics for diclofenac potassium

\begin{tabular}{lllllllll}
\hline $\begin{array}{l}\text { Nominal conc. }(\boldsymbol{\mu g} \\
\left.\mathbf{m L}^{-1}\right)\end{array}$ & $\mathbf{0 . 2 5}$ & $\mathbf{0 . 5 0}$ & $\mathbf{1 . 0 0}$ & $\mathbf{2 . 5 0}$ & $\mathbf{5 . 0 0}$ & $\mathbf{1 0 . 0 0}$ & $\mathbf{2 0 . 0 0}$ & $\mathbf{4 0 . 0 0}$ \\
\hline $\begin{array}{l}\text { Mean observed } \\
\text { conc. }\left(\mu \mathrm{g} \mathrm{mL}^{-1}\right)\end{array}$ & 0.33 & 0.57 & 0.93 & 2.13 & 4.70 & 10.67 & 19.80 & 39.93 \\
SD & 0.12 & 0.06 & 0.06 & 0.06 & 0.17 & 0.50 & 0.20 & 0.12 \\
SEM & 0.07 & 0.03 & 0.03 & 0.03 & 0.10 & 0.29 & 0.12 & 0.07 \\
$95 \% \mathrm{Cl}(\mathrm{L})$ & 0.05 & 0.42 & 0.79 & 1.99 & 4.27 & 9.42 & 19.30 & 39.65 \\
$95 \% \mathrm{Cl}(\mathrm{U})$ & 0.62 & 0.71 & 1.08 & 2.28 & 5.13 & 11.92 & 20.30 & 40.22 \\
RSD & 34.65 & 10.19 & 6.19 & 2.71 & 3.69 & 4.72 & 1.01 & 0.29 \\
\hline
\end{tabular}


Sarfraz et al

Table 5: Inter-day statistics for diclofenac potassium

\begin{tabular}{lllllllll}
\hline $\begin{array}{l}\text { Nominal conc. }(\boldsymbol{\mu g} \\
\left.\mathbf{m L}^{-1}\right)\end{array}$ & $\mathbf{0 . 2 5}$ & $\mathbf{0 . 5 0}$ & $\mathbf{1 . 0 0}$ & $\mathbf{2 . 5 0}$ & $\mathbf{5 . 0 0}$ & $\mathbf{1 0 . 0 0}$ & $\mathbf{2 0 . 0 0}$ & $\mathbf{4 0 . 0 0}$ \\
\hline $\begin{array}{l}\text { Mean observed conc. } \\
\left(\mu \mathrm{g} \mathrm{mL} \mathrm{L}^{-1}\right)\end{array}$ & 0.26 & 0.54 & 1.06 & 2.50 & 5.20 & 10.65 & 20.00 & 40.30 \\
SD & 0.02 & 0.04 & 0.03 & 0.04 & 0.10 & 0.64 & 0.00 & 0.21 \\
SEM & 0.01 & 0.02 & 0.02 & 0.02 & 0.06 & 0.37 & 0.00 & 0.12 \\
$95 \% \mathrm{Cl}(\mathrm{L})$ & 0.22 & 0.45 & 0.99 & 2.40 & 4.94 & 9.05 & 20.00 & 39.78 \\
$95 \% \mathrm{Cl}(\mathrm{U})$ & 0.29 & 0.63 & 1.13 & 2.61 & 5.45 & 12.24 & 20.00 & 40.83 \\
\hline
\end{tabular}

\section{DISCUSSION}

From the recovery data, the developed method is suitable for diclofenac potassium and ketoprofen. There were neither overlapping nor interfering peaks at the retention times of the drugs so it was presumed that all the plasma proteins precipitated efficiently during the plasma treatment process. Thus this reduced sample processing time. Although there was variation in bias this may be reduced by treating the samples more carefully during the extraction process. The mobile phase used in this work was so simple and economical; so also was the extraction procedure which was short in duration. Thus, the chances of column damage and degree of human errors were minimal. Recovery of both drugs (diclofenac potassium and ketoprofen) in the different assays under the same pre-set conditions may indicate the suitability of the developed method for NSAIDs and its analogs. Regarding the stability of the drug in human plasma, the intra- and inter day statistics were favourable. The use of sulphuric acid and sodium chloride was critical to the effectiveness of the extraction procedure.

\section{Precautionary measures}

During sample pretreatment, the following precautionary measures must be followed: (a) Molar solutions of $\mathrm{NaCl}$ and $\mathrm{H}_{2} \mathrm{SO}_{4}$ that 24-h old must not be used. It was found that old solutions did not precipitate plasma proteins efficiently. (b) The solutions must be accurately prepared at the exact molar concentrations; otherwise, there will be improper extraction of the drugs from the plasma. (c) Do not inject spiked plasma if it is turbid. (d) Be careful regarding the order of mixing. Any change in mixing order may affect the results.

\section{CONCLUSION}

The proposed method may be applied to routine analysis of diclofenac potassium due to its high sensitivity, specificity, repeatability, reproducibility, robustness and ruggedness. The method is also applicable to ketoprofen which was used as the internal standard (IS). The extraction procedure is especially timesaving for in vivo analysis of NSAIDs.

\section{CONFLICT OF INTEREST}

The authors declare no conflict of interest. No financial support was received for this work by any of the authors

\section{ACKNOWLEDGEMENT}

The authors are grateful to the human volunteers who offered the blood specimens. One of the authors especially acknowledges her husband, Muhammad Sarfraz, who served as a volunteer.

\section{REFERENCES}

1. British Pharmacopoeia, vol. 1, Great Britain, Directorate of Medicine and Health; 2007, $p$ 665.

2. Diclofenac Potassium Tablet, Dailymed, Sandoz Inc, $2007 \quad$ (Available from: http://dailymed.nlm.nih.gov/dailymed/druglnfo. cfm?id=17903) [cited 2007, January 11]

Trop J Pharm Res, October 2011;10(5):668 
3. Hinz B, Chevts J, Renner B, Wuttke H, Rau T, Schmidt A, Szelenyi I, Brune K, Werner U.Bioavailability of Diclofenac Potassium at Low Doses ,Br J Clin Pharmacol. 2004; 59 (1): 80-84, DOI:10.1111/j: 1365-2125.

4. Yamamoto E, Sakaguchi T, Kajima T, Mano N, Asakawa N. Methylcellulose Immobilized Reversed Phase Precolumn for Direct Analysis of Drugs in Plasma by HPLC, Anal Sci. 2001; 17: 1155-1159.

5. McCalley DV. J Chromatogr. A, Analysis of the Cinchona Alkaloids by High-Performance Liquid Chromatography and Other Separation Techniques 2002; 967: 1-19.

6. Arcelloni C, Lanzi $R$, Pedercini S, Molteni G, Fermo I, Pontiroli A, Paroni R. J. High Performance Liquid Chromatographic Determination of Diclofenac in Human Plasma After Solid Phase Extraction, J. Chromatogr. B, 2001; 763: 195-200.

7. El-Samaligy MS, Yahia SA, Basalious EB. Formulation and Evaluation of Diclofenac Sodium Buccoadhesive Discs, Int. J Pharm. 2004; 286: 27-39.

8. Valliappan K, Kannan K, Sivakumar T, Manavalan R. Enantiospecific Pharmacokinetic Studies on Ketoprofen in Tablet Formulation Using Indirect Chiral HPLC Analysis, J. Appl. Biomed; 2006; 4 (3): 153-161.

9. Brooks KE and Smith NB. Eficient extraction of basic, neutral and acidic drugs from plasma for analysis by gas chromatography-mass spectrometry, Clin. Chem. 1991;37(11): 197578.

10. Quelroz MEC and Lancas FM. Practical tips on preparing plasma samples for drug analysis using SPME, LCGC North America 2004; 22. www. chromatographyonline.com

11. Guideline on Validation of Bioanalytical Methods, European Medicines Evaluation Agency EMEA, London, UK, 2009.

12. Chmielewska A, Konieczna L, Plenis $A$, Lamparczyk $H$. Sensitive Quantification of
Chosen Drugs by Reversed Phase Chromatography with Electrochemical Detection at $A$ Glassy Carbon Electrode, J. Chromatogr. B, 2006; 839: 102-111.

13. Reviewer Guidance: Validation of Chromatographic Methods, CDER, FDA, 1994.

14. Boisvert J, Caillé G, McGilveray IJ, Qureshi SA. Quantification of Ketoprofen Enantiomers in Human Plasma Based on Solid Phase Extraction and Enatioselective Column Chromatography, J. Chromatogr. B, 1997; 690: 189-193.

15. Guidance for Industry: Bioanalytical Method Valdiation, FDA (CDER), 2001

16. Venkatesh $P$, Kumar RR, Rajesekaran A,Dharman DJ, Bioanalytical Method Development and Comparative Bioavailability Study of Clozabam Tablets in Albino Rates Plasma Using RPHPLC Method, Digest J Nanomat Biostructures, 2010; 5 (2): 403-409.

17. Song $M$, Wang $L$, Zhao $H$, Hang $T$, Wen $A$, Yang $L$, Jia L, Rapid and Senstive Liquid Chromatorgraphy-Tandem Mass Spectrometry: Assay Development, Validation and Application to a Human Pharmacokinetic Study, J. Crhomatogr. B, 2008; 875: 515-521.

18. Sun $Y$, Takaba K, Kido H, Nakashima MN, Nakashima K, Simultaneous Determination of Arylpropionic Acid NSAIDS in pharmaceutical formulations and Human Plasma by HPLC with UV Detection, J Pharm Biomed Anal, 2003; 30: 1611-1619.

19. Tettey-Amlado RNO, In-Vitro Release of Ketoprofen from Preparatory and Extemporaneously Manufactured Gels (Thesis), Rhodes University, Grahamstown, SA, 2005.

20. Welink J, Analytical Considerations, Training Workshop: Assessment of Interchangeable Multisource Medicines, World Health Organization (WHO), 2009. PPT 